\title{
Associations between exposure to Information and Communication Technology (ICT) and reported discomfort among adolescents
}

\author{
Kristy Palmer ${ }^{\mathrm{a}}$, Marina Ciccarelli ${ }^{\mathrm{a}, *}$, Torbjorn Falkmer ${ }^{\mathrm{a}, \mathrm{b}, \mathrm{c}, \mathrm{d}}$ and Richard Parsons ${ }^{\mathrm{a}}$ \\ ${ }^{a}$ School of Occupational Therapy and Social Work, Curtin Health Innovation Research Institute, Curtin University, \\ Perth, WA, Australia \\ ${ }^{\mathrm{b}}$ Rehabilitation Medicine, Department of Medicine and Health Sciences, Faculty of Health Sciences, Linköping \\ University and Pain and Rehabilitation Centre, UHL, County Council, Linköping, Sweden \\ ${ }^{c}$ School of Health Sciences, Jönköping University, Jönköping, Sweden \\ ${ }^{\mathrm{d}}$ School of Occupational Therapy, La Trobe University, Melbourne, VIC, Australia
}

\begin{abstract}
.
BACKGROUND: Use of Information and Communication Technologies (ICT) are common among adolescents in their daily activities.Exposure to ICT has been associated with discomfort and musculoskeletal disorders in adults, with growing concern about the potential risks to children and adolescents' physical health.

OBJECTIVE: The objectives of this study were to (i) quantify self-reported discomfort and exposure to ICT among adolescents; and (ii) determine if associations exist between discomfort and levels of exposure.

PARTICIPANTS: The participant group comprised 33 Australian adolescents aged 12-15 years.

METHODS: The study used self-reports by participants for a one week period. Intensity and location of discomfort was reported via a written discomfort log. ICT exposure and physical activity were reported through an electronic time-use diary.

RESULTS: The most common ICT types reported by participants were television, mobile phones and desktop and laptop computers. Discomfort was reported by $86 \%$ of participants. The most frequently reported areas were the legs, head/neck, back and shoulders. There was no statistical association found between ICT exposure and discomfort. The majority of participants exceeded the recommended 60 minutes per day of moderate to vigorous physical activity.

CONCLUSIONS: High exposure to ICT and high prevalence of low level discomfort was reported by the participants. Participating in regular physical activity may have some protective effect against ICT-related discomfort.
\end{abstract}

Keywords: Adolescents, information and communication technologies, musculoskeletal discomfort, self-report

*Corresponding author: Marina Ciccarelli, School of Occupational Therapy and Social Work, Curtin University, GPO Box U 1987, Perth, Western Australia, 6845, Australia. Tel.: +61 89266 3692; Fax: +61 89266 3636; E-mail: M.Ciccarelli@curtin.edu.au.

\section{Introduction}

Information and Communication Technology (ICT) refers to any technologies that access, store or communicate information [1]. This includes devices such as desktop and laptop computers, mobile telephones, television (TV) and electronic gaming consoles. The 
current generation of adolescents access and use these technologies in their home, school and community environments [2]. The period of adolescence includes the onset of puberty until legal adulthood; i.e., 18 years of age. Puberty can commence in some children as early as 11 years [3]; but for the purpose of this paper, adolescents refers to young people aged between 12 and 17 years. Adolescents use ICT for a variety of reasons, including their leisure activities, to communicate and connect with their peers [4], and to complete academic work [5].

The range of ICT devices is expanding and becoming more affordable for Australian households [6]. In Australia between 1998 and 2008, access to the Internet in the home increased from $16 \%$ to $72 \%$ [7]. Internet access increases by age; with $60 \%$ of 5 to 8 year old Australian children accessing the Internet in 2009 compared with $96 \%$ of adolescents aged 12 to 14 years [8]. Eighty-eight per cent of Australian adolescents aged 15-17 years use digital technologies to access social networking sites [5]. Use of computers was reported to be more than seven hours per week, by over a third of the 884 Australian adolescent participants in a study published in 2006 [9]. In 2009, another study of 925 Australian adolescents aged 1319 years (mean age 16.1 years) found that digital technologies were used on average, for over three hours per day [10]. The replacement of physical activity with more sedentary screen-based activities among adolescents is also a concern, since findings show that adolescents are two to three times more likely to watch TV than participate in physical activity [11]. The 2010 Kaiser Family Foundation Survey of approximately 2,000 young people aged $8-18$ years in the USA suggests that other forms of ICT (i.e., computers, gaming devices, mobile telephones) do not replace, but are used in addition to, TV watching [12]. With the emergence of multi-purpose single interface devices such as tablets and smart phones, adolescents' exposure to ICT is likely to increase as devices become more portable and further integrated into activities of daily living.

Much of the data of children's ICT exposure are based on self-report measures; with concerns about the validity and reliability of reported frequencies and durations of exposure. However, a recent study demonstrated that end-of-day self-reported exposure to different activities and type of ICT used, among 9-10 year olds was both reliable and valid [13]. Although the participants in that study were pre-adolescent, the findings suggest the use of an end-of day-diary to document exposure may be a more suitable outcome measure for an adolescent population, than using a questionnaire asking about exposure in the past month [14] or estimations of average daily use [15-17].

Increased ICT exposure can potentially lead to negative health outcomes. The psychological health impacts of ICT use on adolescents have been raised in the literature [18-20], and in the last decade the potential physical and musculoskeletal health concerns have been increasingly reported in the scientific literature $[9,10,15,21-26]$. Discomfort is frequently reported by adolescent users of ICT. In a study of adolescents aged between 12 and 15 years, $41 \%$ reported experiencing computer-related discomfort [2]. An even higher prevalence $(68 \%)$ of musculoskeletal discomfort related to using computers was found in Hong Kong [24]. Self-reports of discomfort have been used in prior studies of adolescents, with the most common areas of discomfort among adolescent users of ICT being the neck [9,27-30], back [27,28,30], and eyes [27, $29,30]$. Children as young as 8 years are considered able to provide reports of their health, well-being and symptoms that are as reliable as proxy reports from parents, when using measures specifically designed for the children's age [31]. In fact, children may be more reliable than their parents in their health reports over time [32].

Temporal exposure to ICT comprises two factors: frequency and duration of use [14]. Duration of exposure to ICT is considered a potential risk factor for discomfort [24] and several studies have found an increased incidence of discomfort with increased ICT task duration [27,33,34]. Musculoskeletal symptoms may also increase based on the frequency and duration of ICT use [2,34].

Musculoskeletal complaints can negatively affect a person's quality of life and productivity [28,29]. Since childhood musculoskeletal pain is a strong predictor for chronic pain in adulthood [35], it is important that childhood complaints associated with ICT are minimised. Adolescents' musculoskeletal systems are still developing and they use ICT in different ways to adults [36,37], so it is imperative that evidence specific to young people's use of ICT is generated. The formation of healthy habits surrounding ICT use is vital in adolescence, as these habits are likely to continue into adulthood [38].

Understanding how young people typically spend their time and the types of activities in which they engage is important in understanding the potential impact to their physical health and well-being. Prior research has explored how 10 year old children participated in 
different ICT and non-ICT tasks when at school and away-from-school [13]; however, less is known about the frequency and duration of ICT exposure and discomfort among adolescents. The first objective of this study was to quantify adolescents' self-reported exposure to ICT, the amount of daily physical activity in which they participate, and their musculoskeletal discomfort. The second objective was to determine any associations between the reported discomfort and exposure to ICT tasks.

\section{Methods}

\subsection{Study design and sampling}

This was a correlation study of Australian adolescents aged 12-15 years. A total sample of 33 participants was achieved via convenience and snowball sampling, which allowed an $r$-value of 0.28 or larger to be detected with a statistical power of $80 \%$, and a critical alpha level of 0.05 . To be eligible for inclusion participants used ICT at least once per week, for a minimum of 15 minutes at a time, in their normal activities. Any potential participants with a pre-existing diagnosed musculoskeletal disorder were excluded from the study.

Informed written parent/guardian consent and the participants' written assent were obtained prior to data collection. All contact was made via the participants' parent/guardian, through their nominated contact details. The outcome measures and consent form were mailed to the parent/guardian, and reminders were sent via email. Ethics approval for the study was granted by the Curtin Human Research Ethics Committee, Perth, Western Australia.

\subsection{Outcome measures}

Participant demographics were collected through a questionnaire that was mailed with the consent form and other self-reported outcome measures to the 33 participants. The questionnaire recorded demographic data such as age, gender, the types of ICT regularly used, and if they were required to use a laptop (i.e., notebook) computer daily during class at school and for homework.

ICT exposure was self-reported by each participant in 15 minute blocks of time for a period of one week. This was recorded in an electronic time-use diary at the end of each day. The diary was in the form of a Mi- crosoft Excel spread sheet that had been emailed to the participant's parent/guardian upon return of the completed consent form. Completing the diary involved participants colour blocking sections of the diary to represent the time spent each day using different types of ICT, and participating in physical activity. Types of ICT included laptop computer, desktop computer, mobile telephone, watching TV, Nintendo Wii, portable hand-held gaming devices and non-portable hand-held gaming devices. Physical activity was defined as moderate to vigorous physical activity that made the participants "huff and puff". A separate worksheet in Excel was used for each day of the week in an attempt to prevent participants from copying data from the previous day's diary.

Discomfort was self-reported by participants on a body map (with front and rear views) for each morning on rising and each night prior to bed, during the same week that they completed the electronic time-use diary. Participants identified the location of discomfort by circling the area(s) that best represented the discomfort experienced. A numeric rating scale was used to assign a discomfort rating to each body part circled. The 11-point scale was anchored with values similar to that which would be found on a Visual Analogue Scale (VAS); i.e., $0=$ no discomfort and $10=$ extreme discomfort. Prior research identified that the numeric rating scale is as sensitive a pain measurement tool as the VAS, but is simpler to use and has a lesser failure rate [40], and that for children aged 8-15 years, a $10 \mathrm{~mm}$ difference on the VAS was required to detect a clinically significant difference [40]. Thus the numeric rating scale was selected in preference to the VAS to measure discomfort in this study.

\subsection{Data processing}

Colour blocks in the electronic time-use-diary were counted for each day, giving the total time spent each day using each type of ICT and time spent participating in physical activity. For the purpose of analysing the locations of discomfort that participants drew on the body maps, sections of the body map were collapsed into broad areas: head/neck; eyes; shoulder; back; upper arm; forearm; hand; leg; abdomen, and 'other'. These broad categories were based on body discomfort/pain locations reported in various prior studies of adolescent ICT users [24,27,41,42].

\subsection{Data analyses}

Data were analysed using the Predictive Analytics SoftWare (PASW) Statistics package and SAS ver- 
sion 9.2 (SAS Institute, Cary, NC, USA, 2008). The Kolmogorov-Smirnov test was used to assess the distributional assumption of normality. Age, exposure to TV watching, exposure to other ICT devices, and physical activity data were normally distributed. Pearson's $\chi^{2}$ test was used to assess any association between gender and different ICT use. Where the expected frequencies were small (e.g., for laptop computer, Nintendo Wii and non-portable gaming device use), Fisher's Exact Tests were used instead. The independent sample t-test was used to compare the mean age and physical activity time between females and males. Pearson's correlation coefficients and their $p$-values were calculated to assess the significance of any possible correlations between age and exposure to TV, exposure to ICT, and physical activity. A random effects regression model was used to assess any differences in ICT use over the days of the week. The correlations between the sets of observations belonging to the same participant were taken into account (as a random effect).

The General Estimating Equation (GEE) model was used to identify any associations between exposure to ICT and the development of discomfort for each day of the study. In this model, the development of discomfort that was considered to be attributable to ICT use (discomfort in the head, eyes, shoulder, back, forearm, hand or arm), and occurring daily at the end of day was modelled as a function of ICT exposure during that day. The same was done for discomfort related to participation in moderate to vigorous physical activity. Correlations in the data due to the multiple measurements on each participant were taken into account in the model. The critical $\alpha$-value for all tests was set at 0.05 .

\section{Results}

\subsection{Participant demographics}

Nineteen (58\%) females, with an average age of 13.4 years (SD 1.2, range 12-15), and 14 (42\%) males, with an average age of 13.6 years (SD 1.2, range 12$15)$, returned all required data from the demographic questionnaire, the electronic time-use diary, and the discomfort log. There was no statistically significant difference in the proportion of females and males in the sample of 33 participants ( $p=0.95$ ); nor in the age between males and females $(p=0.51)$. Eight $(24 \%)$ of the participants reported they were required to use a laptop (notebook) computer daily in class at school and for homework.

\subsection{Exposure to ICT and physical activity tasks}

Total ICT use on each day was calculated as the total of time spent using each type of device (i.e., desktop computer, laptop computer, mobile telephone, TV, portable hand-held gaming device, non-portable handheld gaming device and Nintendo Wii). Mobile telephone use was frequently reported to be of durations between 40 and 70 minutes. The random effects regression model showed that there was a significant difference in ICT use across the days of the week overall $(p<0.0001$ ), with weekend days (Saturdays and Sundays) showing significantly higher use than each of the other days (all pairwise $p$-values $<0.005$ except for Monday vs. weekend: $p=0.036$ ). Daily total hours spent using ICT varied from 4.7 for weekend days, to approximately 3.0 hours per day for other days. ICT use on Mondays was intermediate ( 3.8 hours). Physical activity showed no association with days of the week $(p=0.85)$. The different ICT types are shown in Table 1, ranked according to reported use in the demographic questionnaire, alongside actual recorded use during the data collection week.

There were no differences between females and males regarding regular use of TV $(100 \%$ use in both groups), laptop computers $(p=0.44)$, mobile telephones $(p=0.17)$, desktop computers $(p=0.80)$, portable hand-held gaming devices $(p=0.062)$, and Nintendo Wii games $(p=1.0)$. There was, however, a difference in the percentage of males $(71 \%)$ reporting they used non-portable hand-held gaming devices compared to $0 \%$ of females $(p<0.0001)$. The ICT use data were subsequently divided into TV and other ICT exposure categories. There were no differences in exposure to TV between males ( 86 minutes per day) and females (91 minutes per day; $p=0.85$ ) and no correlation between age and exposure to TV $(r=-0.1$, $p=0.60$ ). Average exposure to other ICT (excluding TV) was greater for males (302 minutes per day) than females (195 minutes per day; $p=0.005$ ), but age and exposure to other ICT was not correlated $(r=-0.1$, $p=0.76$ ).

Exposure to physical activity was also recorded during the period of data collection. All participants reported participating in physical activity at least once during the week, on average 108 minutes per day (SD $=53.9$ ) ranging from 2 to 229 minutes. As age increased, physical activity decreased $(r=-0.4, p=$ $0.02)$. There were no differences in exposure to physical activity between males (104 minutes per day) and females (111 minutes per day; $p=0.69$ ). 
Table 1

Rank ordering of activity according to regular use (reported in demographic questionnaire) and use over the seven day measurement period (reported in task diary)

\begin{tabular}{lcccc}
\hline Type of activity & $\begin{array}{c}\text { Participants reporting } \\
\text { regular use } n(\%)\end{array}$ & $\begin{array}{c}\text { Participants reporting } \\
\text { use over seven days }(\%)\end{array}$ & $\begin{array}{c}\text { Mean (SD) minutes per day } \\
\text { of use over seven days* }\end{array}$ & $\begin{array}{c}\text { Median (range) minutes per } \\
\text { day of use over seven days* }\end{array}$ \\
\hline TV watching & $33(100 \%)$ & $32(97 \%)$ & $89(68)$ & $77(9-384)$ \\
Laptop computer use & $24(73 \%)$ & $21(64 \%)$ & $65(67)$ & $36(6-234)$ \\
Mobile phone & $19(58 \%)$ & $11(33 \%)$ & $26(27)$ & $26(2-84)$ \\
Desktop computer use & $18(55 \%)$ & $24(73 \%)$ & $71(119)$ & $32(4-446)$ \\
Portable hand-held gaming & $15(45 \%)$ & $14(42 \%)$ & $29(26)$ & $21(2-94)$ \\
Non-portable gaming & $10(30 \%)$ & $6(18 \%)$ & $77(55)$ & $81(4-139)$ \\
Nintendo Wii & $8(24 \%)$ & $6(18 \%)$ & $27(25)$ & $24(2-71)$ \\
Physical activity & $\#$ & $33(100 \%)$ & $108(54)$ & $103(2-229)$ \\
\hline
\end{tabular}

*Minimum time-use diary resolution 15 minutes; non-users were excluded from this calculation. \#Data not collected in questionnaire.

\subsection{Discomfort reports}

Of the 33 participants, 31 (94\%) self-reported experiencing discomfort at least once during the seven day data collection period. Discomfort reports are further described in Table 2. Discomfort scores rated on the 0 10 numeric rating scale were recorded for each participant twice per day (morning and end of day); thus the maximum number of reported incidents of discomfort was 462 for the 33 participants over seven days. The number of participants reporting discomfort on each day was calculated and the mean number (across days) is reported in the Table 2 . Note that the mean daily discomfort scores were calculated by averaging the mean scores obtained on each day. Days where no discomfort was recorded in a given body area were excluded from the calculation.

As previously mentioned, discomfort was divided into three body areas corresponding to task diary information, shown in Table 2. For further analyses, discomfort reported in the back, shoulders and arms was disregarded; since the origin of the discomfort may have been either ICT use or physical activity, based on prior studies reporting the body location of adolescents' discomfort associated with these activities. The average physical activity- related discomfort was 0.20 $(\mathrm{SD}=0.3)$ in the morning (based on all 33 participants, 15 of whom experienced no discomfort), and $0.33(\mathrm{SD}=0.4)$ at the end of day. The corresponding mean end of day ICT-related discomfort was 0.18 (SD $=0.2$ ). There were no differences between males and females in any of the categories of self-reported discomfort in the morning (due to physical activity; $p=$ 0.38 ), or at the end-of-day (due to physical activity; $p=0.56$ or due to ICT; $p=0.57$ ). The (paired) differences between morning and end-of-day discomfort due to physical activity differed between genders, with females experiencing an increase in discomfort from morning to evening, while the males showed no change $(p=0.030)$. Age did not correlate with either form of self-reported discomfort (morning discomfort due to: physical activity $r=0.0-0.09, p=0.63$; end-of-day discomfort due to physical activity: $r=-0.03 ; p=$ 0.89 and ICT $r=0.27 ; p=0.13$ ). There was also no evidence of correlation between end-of-day discomfort due to physical activity and discomfort due to ICT use $(r=0.09, p=0.59)$.

\subsection{Associations between discomfort and physical activity exposure or ICT exposure}

To determine if any associations existed between reported ICT exposure and discomfort, a GEE model was fitted to the daily data. In this model, the presence of discomfort in the areas of the body commonly affected by ICT use was the dependent variable, and exposure to ICT and physical activity were the independent variables.

Exposure to physical activity and end of day physical activity-related discomfort were not significantly correlated ( $r=-0.34 ; p=0.056)$; although the trend was in a negative direction suggesting that those who participated in moderate to vigorous physical activity more tended to experience less discomfort. Similarly, no significant correlation was found between ICT use and ICT-related discomfort $(r=-0.01 ; p=0.97)$. However, ICT-related discomfort correlated negatively with exposure to physical activity $(r=-0.44, p=$ $0.011)$. Hours of watching TV was positively correlated with ICT-related discomfort $(r=0.46, p=$ 0.009).

No significant association was identified between amount of ICT use during each day and end of day discomfort in the areas of the body commonly affected by ICT use such as the head, neck, shoulders, upper back and arms/hands $(r=0.01, p=0.86)$. There was a sig- 
Table 2

Self-reported discomfort by location; (0-10 score)

\begin{tabular}{|c|c|c|c|c|c|}
\hline \multirow[t]{2}{*}{ Discomfort location } & \multirow{2}{*}{$\begin{array}{c}\text { Total incidents of } \\
\text { discomfort ( } n \text { reporting) }\end{array}$} & \multicolumn{2}{|c|}{ Morning } & \multicolumn{2}{|c|}{ End-of-day } \\
\hline & & $\begin{array}{l}\text { Mean number } \\
\text { reporting discomfort } \\
\text { per day (range) }\end{array}$ & $\begin{array}{l}\text { Mean discomfort } \\
\text { score (range) }\end{array}$ & $\begin{array}{l}\text { Mean number } \\
\text { reporting discomfort } \\
\text { per day (range) }\end{array}$ & $\begin{array}{l}\text { Mean discomfort } \\
\text { score (range) }\end{array}$ \\
\hline Legs & $103(23)$ & $6.0(3-9)$ & $3.1(2.7-3.7)$ & $8.7(8-10)$ & $3.5(2.8-4.4)$ \\
\hline Head/neck & $88(19)$ & $6.0(4-8)$ & $3.1(2.3-4.5)$ & $6.6(5-8)$ & $2.7(2.1-3.5)$ \\
\hline Back & $72(18)$ & $5.0(3-7)$ & $2.6(2.0-3.0)$ & $5.3(4-7)$ & $2.7(1.8-3.4)$ \\
\hline Shoulders & $43(17)$ & $3.0(1-6)$ & $1.6(1.0-3.0)$ & $3.1(1-5)$ & $3.0(1.8-6.0)$ \\
\hline Eyes & $22(8)$ & $0.7(0-2)$ & $2.3(2.0-3.0)$ & $2.4(1-6)$ & $2.0(1.0-3.0)$ \\
\hline Arms & $10(7)$ & $0.9(0-3)$ & $2.8(2.0-4.0)$ & $0.6(0-2)$ & $4.0(2.0-7.0)$ \\
\hline Abdomen & $5(3)$ & $0.1(0-1)$ & $3.0(3.0-3.0)$ & $0.6(0-1)$ & $3.5(1.0-7.0)$ \\
\hline Forearm & $3(3)$ & $0.4(0-1)$ & $1.3(1.0-2.0)$ & 0 & \\
\hline Hand & $6(3)$ & $0.6(0-2)$ & $1.8(1.0-3.0)$ & $0.3(0-2)$ & $1.5(1.5-1.5)$ \\
\hline Other & $2(1)$ & $0.1(0-1)$ & $2.0(2.0-2.0)$ & $0.1(0-1)$ & $2.0(2.0-2.0)$ \\
\hline
\end{tabular}

nificant association between participation in any physical activity on a given day and reporting end of day discomfort on that day ( $p=0.04)$. The coefficient for 'no physical activity' was 0.8 (95\% CI: 0.05 to 1.6 ), so that participants who participated in no physical activity had a greater chance of experiencing ICT-related discomfort than those who undertook some physical activity.

\section{Discussion}

This study found that ICT exposure was high among the study participants. Use of ICT (excluding TV) and especially non-portable hand-held gaming devices, such as PlayStation ${ }^{\circledR}$ and Xbox was higher among the males than females; similar to previous reports [33]. The most popular type of ICT used during the oneweek data collection period was TV, with every participant reported watching TV; a finding that was expected and also confirmed by others [11]. One quarter of participants reported in the demographic questionnaire that their respective schools required them to use a laptop computer for daily in-class and homework activities, and so it was expected that there would be frequent reporting in the time-use diaries of laptop computers use. Desktop computers and mobile telephones were the other ICT types also frequently reported in the time-use diaries.

The relatively long period of time reportedly spent each day using a mobile telephone (between 4070 minutes) could be explained by the purpose of its use. With the emergence of smart phone technology, mobile telephone devices are no longer used purely for messaging and calling people but also for accessing the internet and gaming [43]. This additional functionality is likely to increase the duration of exposure to these particular ICT devices.

Participants in our study reported using ICT frequently and for long durations of time before taking a break; both of which are considered risk factors for increased musculoskeletal discomfort [44]. Discomfort prevalence was high among the sample; with nearly all participants reporting discomfort at least once during the study. The most commonly reported areas of the body being the head/neck, back and shoulders, similar to prior reports from child and adolescent ICT users $[27,45,46]$. Females tended to have increasing discomfort related to physical activity from start of day to end of day; whereas, males reported little change in the presence, location and intensity of discomfort over time. Despite the high prevalence of discomfort and high ICT exposures reported by participants, no statistical association was found between ICT exposure and reported discomfort.

Our study found that increasing age was associated with a decline in levels of moderate to vigorous physical activity among both male and female participants; a finding supported by others [47]. However, despite being high users of ICT, the mean durations of physical activity among both male and female participants exceeded the Australian government minimum recommendations of one hour per day of moderate to vigorous physical activity among children and youth [48]. Participation in physical activity appeared to have a protective effect for ICT-related discomfort, among our study participants. Such an association between highlevel physical activity in childhood and a reduced likelihood of developing back pain in adolescence has been reported by others [49], and our study adds to the research evidence by identifying the health benefits of physical activity in lowering risk for musculoskeletal 
discomfort among high users of ICT. Males and females in our study watched similar amounts of TV during the study period, and an increase in sedentary TV watching was associated with an increase in their reported ICT-related discomfort. Prior studies also found high exposure to TV watching was associated with an increased risk of low back pain [50,51] among adolescents.

When interpreting the findings of this study, a number of potential limitations should be considered. The study was based on self-report outcome measures, relying on the participants' recall of time use and discomfort and remembering to complete the electronic time-use diary and discomfort log in a timely manner.

There was some discrepancy between the types of ICT participants reported they regularly used in the demographic questionnaire completed prior to filling out the time-use diary, and the types of ICT reported in the one-week time-use diaries. This may be due to the limited data collection period that provided only a crosssectional snapshot of the participants' ICT use during one week. The phrase 'regular use' in the demographic questionnaire was not defined, and therefore may have been interpreted differently by participants. For example, in the demographic questionnaire, participants reported more hours of regular mobile telephone use than in the time-use diary. These differences may have also been associated with participant recall and sensitivity of the electronic time-use diary. For example, mobile telephones (and other types of ICT) may in fact have been used more frequently than reported in the diaries; but some occurrences may have been for less than the 15 minute increments in the time-use diary. As a consequence, the total duration of mobile telephone use by the participants may have been under-reported.

Another limitation of the time-use diary was that it only allowed one ICT type to be recorded in any time period. In reality, participants may have been using multiple ICT devices simultaneously. This needs to be taken into consideration for future studies, because multi-tasking with ICT is not uncommon among adolescents [52] and may affect the experience of perceived discomfort.

The study measured participants' discomfort scores at the beginning and end of the day; therefore, it was not possible to pinpoint the exact cause of reported discomfort. Although it did provide an insight into whether discomfort increased throughout the day, and whether discomfort may have been episodic or carried over from day to day.

Difficulty in recruiting adolescents willing to complete the time-use diary resulted in a small sample size.
The small number of participants limits the generalizability of the findings beyond the study sample. Future studies should therefore aim to include a larger representative population. There is also a need for longitudinal studies to determine the changes in age-related participation in ICT tasks and physical activity, and the longer term impacts of high ICT exposure on physical well-being among adolescents as they physically mature.

\section{Conclusions}

In conclusion, this study revealed that the prevalence of low level discomfort was high among a sample of 12-15 year old Australian adolescents. The most frequently reported areas of discomfort were the legs, head/neck, back and shoulders. The types of ICT most used during the one week study were TV, desktop and laptop computers, mobile telephones and portable hand-held gaming devices. There was a large variation in terms of exposure to each ICT type between days. Most study participants reported high exposure to ICT tasks (based on frequency and duration of use); however, there was no statistical association found between the level of exposure to ICT and discomfort reported. The majority of participants met the Australian guidelines for engagement in daily moderate to vigorous physical activity, which may have had a protective effect on the intensity of ICT-related discomfort reported. There is a need for future studies to involve a larger representative sample population in order to gain a better understanding of the association between ICT exposure and discomfort.

\section{Acknowledgements}

This study comprised the research project component of the Bachelor of Science in Occupational Therapy (Honours) degree for the first author. The study was funded by the School of Occupational Therapy and Social Work at Curtin University.

\section{References}

[1] Australian Bureau of Statistics. 8126.0 - Information and communication technology, Australia. Canberra 2008 [updated 3 October 2008; cited 201015 September]; Available from: http://www.abs.gov.au/AUSSTATS/abs@.nsf/Lookup/ 8126.0Main+Features12006-07?OpenDocument. 
[2] Jacobs K, Hudak S, McGiffert J. Computer-related posture and musculoskeletal discomfort in middle school students. Work. 2009;32:275-83.

[3] Lu PW, Briody JN, Ogle GD, Morley K, Humphries IRJ, Allen J, et al. Bone mineral density of total body, spine, and femoral neck in children and young adults: A cross-sectional and longitudinal study. Journal of Bone and Mineral Research. 1994;9(9):1451-8.

[4] Australian Bureau of Statistics. 8146.0 - Household Use of Information Technology, Australia, 2010-11. Canberra 2011.

[5] Straker L, Pollock C. Optimizing the interaction of children with information and communication technologies. Ergonomics. 2005;48(5):506-21.

[6] Australian Bureau of Statistics. 4102.0 - Australian Social Trends. Canberra 2011 [updated 29 June; cited 2012 29 June]; Available from: http://www.abs.gov.au/AUSSTATS/ abs@.nsf/Lookup/4102.0Main+Features50Jun+2011.

[7] Australian Bureau of Statistics. 8146.0 - Household use of Information Technology, Australia, 2008-09. Canberra: Australian Bureau of Statistics; 2009; Available from: http://abs. gov.au/ausstats/abs@.nsf/mf/8146.0/.

[8] Australian Bureau of Statistics. 4901.0 -Children's participation in cultural and leisure activities, Australia Canberra: Australian Bureau of Statistics; 2009 [cited 200912 November]; Available from: http://www.abs.gov.au/ausstats/abs@.nsf/ Products/4901.0 Apr+2009 $\sim$ Main+Features $\sim$ Children's+ activities+over+time? OpenDocument.

[9] Straker L, O’Sullivan P, Kendall G, Sloan N, Pollock C, Smith A, et al. ITKids: exposure to computers and adolescents' neck posture and pain. In: Koningsveld E, editor. Proceedings of the International Ergonomics Association 16th World Congress; Maastrich, Netherlands 2006.

[10] Mathers M, Canterford L, Olds T, Hesketh K, Ridley K, Wake M. Electronic media use and adolescent health and well-being: Cross-sectional community study. Academic Pediatrics. 2009;9(5):307-14

[11] Biddle S, Marshall S, Gorely T, Cameron N. Temporal and environmental patterns of sedentary and active behaviors during adolescents' leisure time. International Journal of Behavioural Medicine. 2009;16:278-86.

[12] Rideout V, Foehr U, Roberts D. Generation $\mathbf{M}^{2}$ : Media in the lives of 8- to 18-year-olds. The Henry J. Kaiser Family Foundation; 2010 [cited 201227 June]; Available from: http:// www.kff.org.

[13] Ciccarelli M, Straker L, Mathiassen S, Pollock C. ITKids Part I: Children's occupations and use of Information and Communication Technologies. Work. 2011;38(4):401-12.

[14] Harris C, Straker L, Smith A, Pollock C. A proposed model representing the relationships between user characteristics, computer exposure and musculoskeletal symptoms in children. Work. 2012;41:838-45.

[15] Zapata A, Pantoja Moraes A, Leone C, Doria-Filho U, Artur C, Silva A. Pain and musculoskeletal pain syndromes related to computer and video game use in adolescents. Eur J Pediatr. 2006;165:408-14.

[16] Diepenmaat A, van der Wal $M$, de Vet $H$, Hirasing $R$. Neck/shoulder, low back, and arm pain in relation to computer use, physical activity, stress, and depression among dutch adolescents. Pediatrics. 2006 February 2006;117(2):412-6.

[17] Milde-Busch A, von Kries, Thomas S, Heinrich S, Straube A, Radon K. The association between use of electronic media and prevalence of headache in adolescents:Results from a population-based cross-sectional study. BMC Neurology. 2010;10.
[18] Li Q. New bottle but old wine: A research of cyberbullying in schools. Computers in human behavior. 2007;23(4):1777.

[19] De Souza Z, Dick G. Disclosure of information by children in social networking - Not just a case of "you show me yours and I'll show you mine". International Journal of Information Management. 2009;29:255-61.

[20] van den Eijnden R, Meerkerk G, Vermulst A, Spijkerman R, Engels R. Online communication, compulsive Internet use, and psychosocial well-being among adolescents: A longitudinal study. Developmental Psychology. 2008;44(3):655-65.

[21] Briggs A, Straker L, Greig A. Upper quadrant postural changes of school children in response to interaction with different information technologies. Ergonomics. 2004;47(7): 790-819.

[22] Burke V, Beilin LJ, Durkin K, Stritzke WGK, Houghton S, Cameron CA. Television, computer use, physical activity, diet and fatness in Australian adolescents. International Journal of Pediatric Obesity. 2006;1(4):248-55.

[23] Hakala P, Rimpelä A, Saarni L, Salminen J. Frequent computer-related activities increase the risk for neck-shoulder and low back pain in adolescents. Eur J Public Health 2006;16(5):536-41.

[24] Siu D, Tse L, Yu I, Griffiths S. Computer products useage and prevelance of computer related discomfort among adolescents. Work. 2009;34:449-54.

[25] Hakala P, Saarni L, Punamaki R-L, Wallenius M, Nygard CH, Rimpela A. Musculoskeletal symptoms and computer use among Finnish adolescents - pain intensity and inconvenience to everyday life: a cross-sectional study. BMC Musculoskeletal Disorders. 2012;13(1):41.

[26] Straker L, O'Sullivan P, Smith A, Perry M. Computer use and habitual spinal posture in Australian adolescents. Public Health Reports. 2007;122(5):634.

[27] Coleman J, Straker L, Ciccarelli M. Why do children think they get discomfort related to daily activities. Work. 2009;32: 267-74.

[28] Erdinc O. Upper extremity musculoskeletal discomfort among occupational notebook personal computer users: Work interference, associations with risk factors, and the use of notebook computer stand and docking station. Work. 2011;39: 455-63.

29] Woods V. Musculoskeletal disorders and visual strain in intensive data processing workers. Occupational Medicine. 2005; 55(2):121-7.

[30] Sommerich C, Ward R, Sikdar K, Payne J, Herman L. A survey of high school students with ubiquitous access to tablet PCs. Ergonomics. 2007;50(5):706-27.

[31] von Baeyer C. Children's self-reports of pain intensity: Scale selection, limitations and interpretation. Pain Research Management. 2006;11(3):157-62.

[32] Riley A. Evidence that school-age children can self-report on their health. Ambulatory Pediatrics. 2004;4(4):371-6.

[33] Burke A, Peper E. Cumulative trauma disorder risk for children using computer products: results of a pilot investigation with a student convenience sample. Public Health Reports. 2002;117(4):350-7.

[34] Harris C, Straker L. Survey of physical ergonomics issues associated with school children's use of laptop computers. International Journal of Industrial Ergonomics. 2000;26(3):33746.

[35] Hestbaek L, Leboeuf-Yde C, Kyvik K, Manniche C. The course of low back pain from adolescence to adulthood: eightyear follow-up of 9600 twins. Spine 2006;31(4):468-72.

[36] Maslen B, Straker L. A comparison of posture and muscle ac- 
tivity means and variation amongst young children, older children and young adults whilst working with computers. Work. 2009;32(3):311-20.

[37] Blackstone J, Karr C, Camp J, Johnson P. Physical exposure differences between children and adults when using standard and small computer input devices. Ergonomics. 2008;51(6):872-89.

[38] Straker L, Pollock C, Maslen B. Principles for the wise use of computers by children. Ergonomics. 2009;52(11):1386-401.

[39] Williamson A, Hoggart B. Pain: a review of three commonly used pain rating scales. Journal of Clinical Nursing. 2005;14(7):798-804.

[40] Powell C, Kelly A, Williams A. Determining the minimum clinically significant differences in visual analog pain score for children. Ann Emerg Med. 2001;37:28-31.

[41] Smith L, Louw Q, Crous L, Grimmer-Somers K. Prevalence of neck pain and headaches: impact of computer use and other associative factors. Cephalalgia. 2009;29:250-7.

[42] Palm P, Hansson R, E, Mortimer M, Palmerud G, Toomingas A, Wigaeus Tornqvist E. Computer use, neck and upperextremity symptoms, eyestrain and headache among female and male upper secondary school students. SJWEH. 2007; Supplement(3):33-41.

[43] Samuelsson U. ICT use among 13-year-old Swedish children. Learning, Media and Technology. 2010;35(1):15-30.

[44] Mathiassen S. Diversity and variation in biomechanical exposure: What is it, and why would we like to know? Applied Ergonomics. 2006;37(4):419-27.
[45] Jacobs K, Baker N. The association between children's computer use and musculoskeletal discomfort. Work. 2001;18(3): 221-6.

[46] Dockrell S, Kelly G. Computer-related posture and musculoskeletal discomfort in schoolchildren. 16th International Ergonomics Association Conference; Maastrich, Netherlands 2006.

[47] Trost S, Pate R, Sallis J, Freedson P, Taylor W, Dowda M, et al. Age and gender differences in objectively measured physical activity in youth. Medicine and Science in Sports and Exercise. 2002;34(2):350-5

[48] Department of Health and Ageing. Australia's physical activity recommendations for 12-18 year olds. Canberra: Commonwealth of Australia; 2004 [cited 201229 June]; Available from: http://www.health.gov.au/internet/main/publishing.nsf/ Content/phd-physical-activity-youth-pdf-cnt.htm.

[49] Wedderkopp N, Kjaer P, Hestbaek L, Korsholm L, LeboeufYde C. High-level physical activity in childhood seems to protect against low back pain in early adolescence. The Spine Journal. 2009;9(2):134-41.

[50] Sjölie A. Associations between activities and low back pain in adolescents. Scand J Med Sci Sports. 2004;4:352-9.

[51] Skoffer B, Foldspang A. Physical activity and low-back pain in schoolchildren. Eur Spine J. 2008;17(3):373-9.

[52] Rideout V, Foehr U, Roberts D. Generation $\mathrm{M}^{2}$ :Media in lives of 8- to 18-year olds. 2010 [cited 201229 June]; Available from: http://www.kff.org/entmedia/upload/8010.pdf. 